\title{
Beira, uma paisagem modernista na África Tropical
}

\author{
Beira, a modernist landscape in Tropical Africa
}

Mário Gonçalves Fernandes ${ }^{[0]}$, Rui Passos Mealha ${ }^{[0]}$, Rui Paes Mendes ${ }^{[0]}$

[a] Universidade do Porto, Porto, Portugal

\section{Resumo}

A Cidade da Beira, é um estudo de caso complexo e ímpar no que se refere à implementação das ideias modernistas em países tropicais. A cidade tornou-se próspera em virtude dos elevados rendimentos providenciados pela sua interface ferro-portuário que a ligava à Rodésia/Zimbabwe e constituía a base da sua riqueza, atraindo jovens ambiciosos e talentosos arquitectos e engenheiros civis portugueses que construíram uma urbe paradoxal, repleta de edifícios modernistas emblemáticos, plenos de complexas e pouco ortodoxas soluções técnicas que preenchem um plano urbanístico único na África colonial portuguesa. Este artigo discute o processo de expansão da cidade assente numa matriz modernista, profundamente influenciado pelo imaginário arquitectónico e urbano brasileiro procurando sublinhar a inscrição da influência modernista na lógica de expansão da cidade como opção técnica e política. Paralelamente discute a importância da circulação das ideias e modelos urbanos e arquitectónicos no meio dos arquitectos e engenheiros civis portugueses radicados em Moçambique. Metodologicamente os autores procederam a um trabalho de campo assente no reconhecimento da matriz da cidade e na identificação do legado arquitectónico modernista de influência brasileira, seleccionando de entre o edificado os exemplos mais emblemáticos.

Palavras-chave: Modernismo. Urbanismo. Morfologia urbana. Urbanismo colonial.

\section{Abstract}

Beira is a complex and unique case study regarding the implementation of modernist ideas in tropical countries. The city became prosperous due to the high yields provided by its rail and port interface connecting to Rhodesia/Zimbabwe; it attracted wealth, ambitious, talented young Portuguese architects and civil engineers that built a paradoxical metropolis, filled with iconic modernist buildings, complex and unorthodox technical solutions that filled an unique urban plan in the Portuguese colonial Africa. This article discusses the city expansion process based on a modernist matrix, deeply influenced by Brazilian architectural and urban imaginary, emphasizing the application of modernist influence in the city's expansion logic as well as technical

MGF é geógrafo, doutor em Geografia Humana, investigador do Centro de Estudos e Ordenamento do Território (CEGOT), Faculdade de Letras da Universidade do Porto, e-mail: mgfernan@letras.up.pt

RPM é arquitecto, licenciado em Arquitectura, investigador do Centro de Estudos de Arquitetura e Urbanismo (CEAU) da Faculdade de Arquitectura da Universidade do Porto, e-mail: rmealha@letras.up.pt

RPM é geógrafo, doutor em Geografia Humana, investigador do Centro de Estudos e Ordenamento do Território (CEGOT), Faculdade de Letras da Universidade do Porto, e-mail: ruipaesmendes@gmail.com 
and political options. It also discusses the importance of the exchange of ideas; and urban and architectural models among Portuguese architects and civil engineers based in Mozambique. The authors methodologically conducted an established recognition fieldwork of the city's matrix and identified the modernist architectural legacy of Brazilian influence by selecting the most emblematic examples among the buildings.

Keywords: Modernism. Urbanism. Urban morphology. Colonial urbanism.

\section{Os constrangimentos na implantação urbana}

A cidade da Beira é um exemplo paradoxal do modelo de colonização preconizado pelos portugueses no continente africano: longe de ser uma cidade sustentada por uma administração central colonial, a Beira deveu a sua concepção urbanística e arquitectónica a uma aliança entre esta e a iniciativa privada, na busca de uma afirmação de prestígio empresarial e urbano.

A sua génese data de 19 de Agosto de 1887 quando, por decisão do governo português da colónia de Moçambique, Portugal afirma a sua soberania na ponta Chiveve, numa estreita faixa de terra arenosa limitada pelos rios Pungué e Búzi. Essa posição obedecia a ditames geoestratégicos numa região onde portugueses e ingleses se posicionavam para conseguir a hegemonia no acesso ao hinterland africano. Nesse local poder-se-ia articular o comércio com o interior do território, fosse pela navegabilidade do rio Pungué, fosse pela construção de uma via férrea ligando o Índico ao interior de África ${ }^{1}$ (Figura 1).

No entanto, a localização para a constituição de uma colónia não era a mais indicada, pois as cheias dos rios limítrofes e as marés vivas do Índico inundavam a povoação. Essa situação recorrente era agravada pelo suporte arenoso no qual assentavam as construções do povoado, sendo este descrito como um "[...] enorme lameiro líquido, gerador de humidades e pestilências, permanentemente ameaçada pelas marés e temporais [...]" (Sopa, 1989, p. 78).

\footnotetext{
${ }^{1}$ No limite, Portugal acalentava o sonho de constituir um enorme território contínuo que unisse o Atlântico ao Índico, ou seja, Angola à Moçambique, sendo esta localização considerada chave para tal objectivo. No entanto, essa pretensão cláudica pela clara oposição que a Grã-Bretanha efectua ao mobilizar as suas forças militares com o intuito de forçar a alteração de posição do governo português. A tibieza com que Portugal reagiu foi um dos motivos que conduziram à sublevação que tornou Portugal uma República.
}

Contra todas as expectativas, será aqui que crescerá aquela que é hoje a segunda cidade de Moçambique, e um dos mais interessantes projectos urbanísticos que os portugueses levaram a cabo, com um vasto conjunto de obras arquitectónicas de cariz modernista e de forte influência brasileira que encontramos naquelas paragens.

A cidade deve grande parte do seu carácter singular à constituição de uma companhia majestática - a Companhia de Moçambique - que, em 1890, obtém a concessão de toda a região, Companhia essa que assume o direito contratual de exercer a soberania integral do território mediante o dever de proceder ao seu desenvolvimento assente em dois vectores:

[...] a construção de um porto e a construção de um caminho-de-ferro, obras que enceta em simultâneo com a protecção e desenvolvimento do núcleo urbano [...] [foram] introduzidas modificações nas moradias, nomeadamente

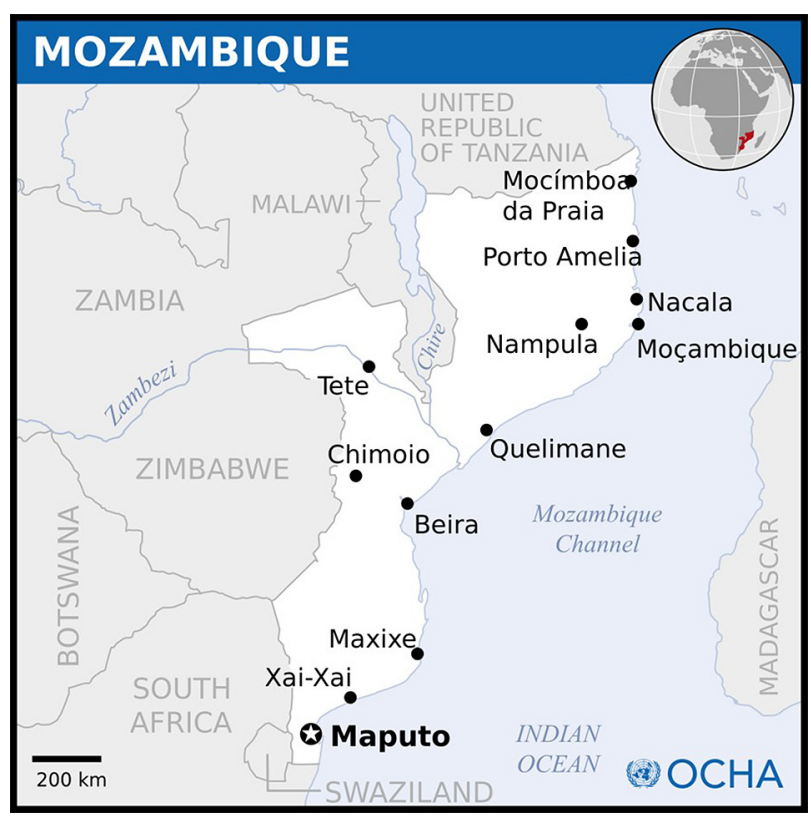

Figura 1 - Moçambique: Principais cidades e países limítrofes Fonte: UN Office for the Coordination of Humanitarian Affairs (OCHA, 2015). 
a construção sobre estacarias [...], assim como a efectivação de uma série de aterros e construção de muralhas que permitem controlar incipientemente a subida das águas, afastando-as das proximidades do casario mas também aumentar a área de expansão urbana (Mendes, 2012a, p. 319).

A então vila, fruto do afluxo de capitais, torna-se um imenso estaleiro que atrai uma vasta mole humana em busca de trabalho e riqueza, gente sedenta de fortuna, que reconhece na urbe e no seu potencial geoestratégico, como plataforma entre o oceano e o interior do continente africano, uma oportunidade para uma vida mais desafogada e próspera (Figuras 2 e 3).

A acção da Companhia de Moçambique na transformação e estruturação da Beira, incluindo territórios limítrofes, foi uma prioridade, assumindo um carácter de urgência, um ponto nuclear para a actividade económica e comercial da Companhia (Figura 4). Assim, a alocação de recursos que permitissem o desenvolvimento do povoado foi intensa e concentrada no tempo

[...] a managerial achievement rare in Africa and unique in Mozambique of establishing a colonial administration on a sound financial bias within the first five years. [...]. Capital was pumped into the Company, its turnover increased dramatically and the colonial economy developed into one of the most active and prosperous in southern Africa (Newitt, 2009, p. 396).

Rapidamente o povoado cresce em dimensão, aumentando as suas funções e importância administrativa², de tal forma que a cidade da Beira se torna o porto natural da economicamente emergente colónia da Rodésia/Zimbabwe, o que atrai a si capitais e cidadãos britânicos e sul-africanos que investem no caminho de ferro entre a Beira e Harare, ficando claro que

[...] a localização do porto da Beira [...] é, em si, e em grande medida, uma questão de ordem estratégica e política à volta da qual gravitaram

\footnotetext{
${ }^{2} 0$ crescimento da Beira foi extremamente rápido: fundada em 1887 por militares que ali estabelecem um pequeno aquartelamento torna-se cidade em 1907, já sob a égide da Companhia de Moçambique, numa altura em que se tornara o mais importante povoado de um imenso território provincial, o qual ia do Índico até às fronteiras das colónias britânicas no interior de África.
}

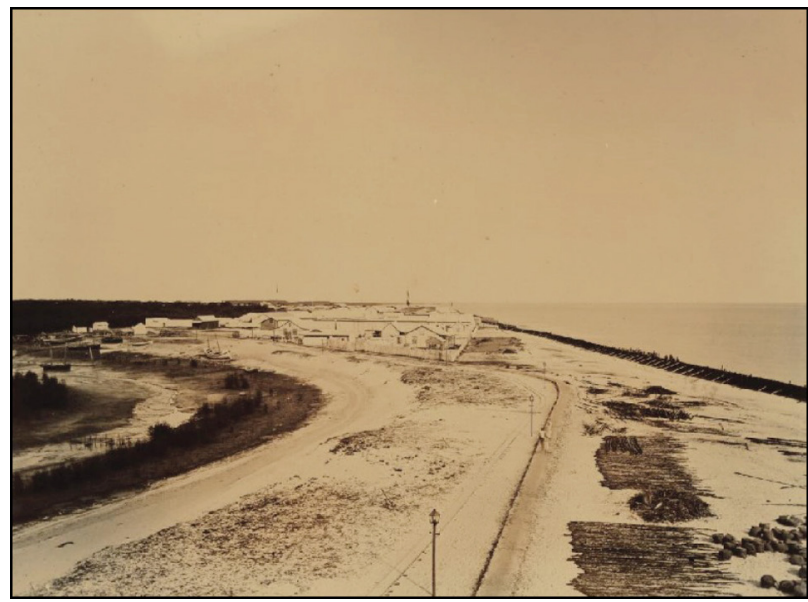

Figura 2 - Panorâmica do núcleo de implantação da vila da Beira em finais do séc. XIX Fonte: Cortesia da Winterton Collection of East African Photographs, Melville J. Herskovits Library of African Studies, Northwestern University, Evanston (Herskovits, 2014).

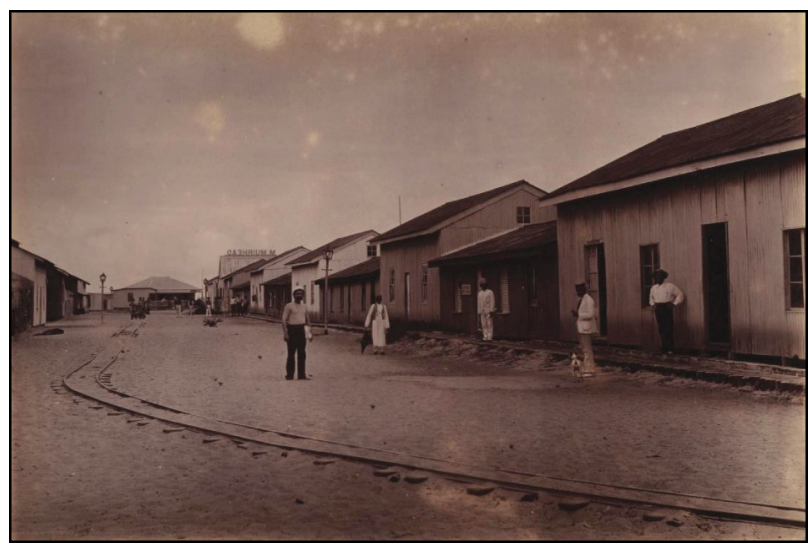

Figura 3 - Interior do núcleo de implantação da vila da Beira em finais do séc. XIX Fonte: Cortesia da Winterton Collection of East African Photographs, Melville J. Herskovits Library of African Studies, Northwestern University, Evanston (Herskovits, 2014).

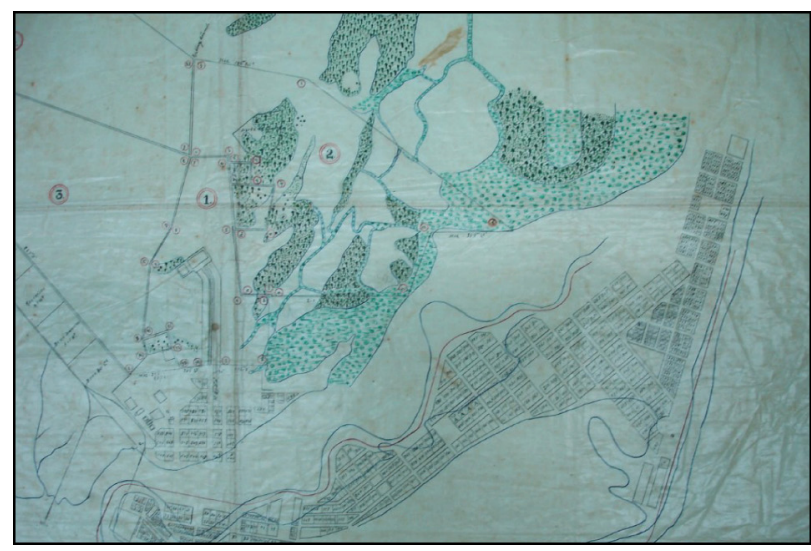

Figura 4 - Projecto de Loteamento da Beira (1898), Pormenor Foto: Arquivo Histórico de Moçambique (2011). 
interesses polivalentes de pessoas singulares e colectivas, sendo o factor económico o mais preponderante, evidenciado pela intervenção sistemática de companhias majestáticas como a British South Africa Company, de Cecil Rhodes, e a Companhia de Moçambique, fundada em 1888, que veio a exercer a administração directa de Manica e Sofala a partir de 1892 (Muhate, 1989, p. 299).

0 crescimento acelerado que o povoado conhece - em especial após a Companhia de Moçambique ali estabelecer a sua sede administrativa e logística - levou a que as autoridades da povoação reconhecessem a necessidade de organizar a sua malha urbana, por forma a acomodar em tão estreita área disponível a população (e mercadorias) que ali demandava, prevendo igualmente a sua expansão, pois era certo que aquela ténue faixa de terra na qual se aninhava a povoação seria insuficiente para a importância que para ela se projectava. Desta forma, em finais do séc. XIX, a Companhia de Moçambique elabora uma planta de urbanização que

[...] define claramente o sentido de desenvolvimento da cidade, o único possível dada a posição geográfica enclavada entre o mar e os rios, definindo igualmente as soluções que se sucederiam nas plantas seguintes: a margem direita do rio destinada ao porto e caminhos-de-ferro e todos os edifícios funcionalmente destes dependentes, e a margem esquerda para áreas residenciais, administrativas e comerciais (Mendes, 2012a, p. 326),

dotando a cidade de uma paisagem urbana até aí desconhecida e que se adaptava de forma resiliente aos condicionalismos impostos pela natureza, cujo plano e edificado decorrentes se ilustram nas Figuras 5 e 6.

Em 1899 eclode a guerra Anglo-Boer e com esta, o porto da Beira assume uma importância primordial para os interesses britânicos. Pois a Beira constitui uma oportunidade para contornar o obstáculo imposto nos acessos à África do Sul, marcando novo afluxo de gentes e capitais que a dotariam de algum cosmopolitismo.

It had become a city with a distinctive British flavour. Hotels, bars and sporting facilities were developed to serve the British community which, after the Portuguese, formed by far the biggest element of the European population. The British character of the town was accentuated by the circulation of sterling currency issued by the Banco de Beira (Newitt, 2009, p. 396).

A importância comercial e os dividendos financeiros provenientes do comércio que absorve levam a que a Beira assuma uma enorme importância no contexto regional nas décadas seguintes. 0 crescimento económico, comercial e demográfico terá reflexo directo na sua malha urbana, seja pela progressiva e rápida expansão da área do porto, seja pelo afluxo de capitais e da fixação de grupos comerciais internacionais que aportam e investem na cidade, criando-se plataformas de armazenamento, áreas comerciais e ampliando-se as áreas residenciais. Para a Companhia de Moçambique, a criação de uma cidade que reflectisse a sua importância crescente no contexto geográfico e político da África portuguesa torna-se

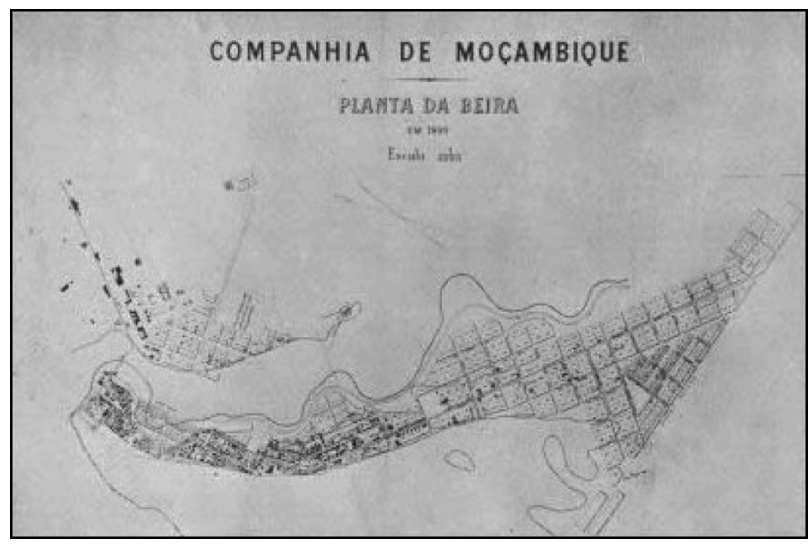

Figura 5 - Plano de Urbanização elaborado pela Companhia de Mocambique (1899)

Fonte: Silveira (n.d.).

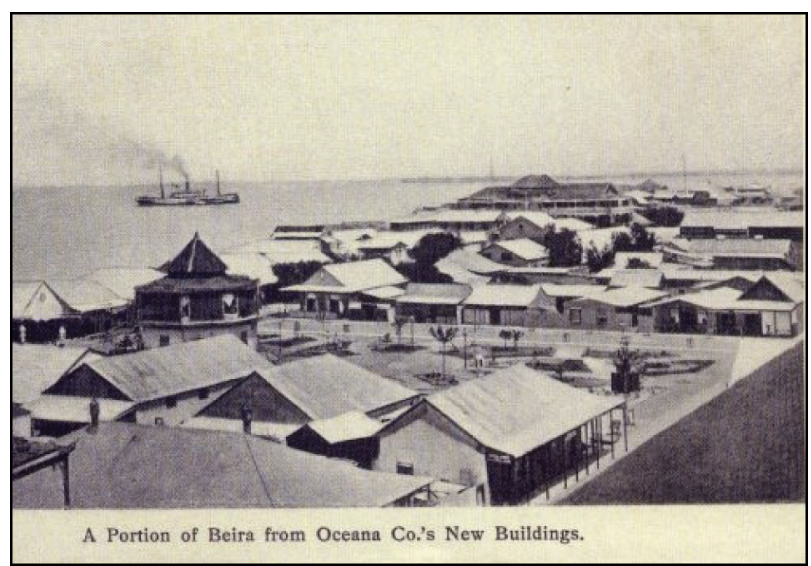

Figura 6 - Beira, Vista parcial (c. 1900)

Fonte: Loureiro (2008). 
uma questão de prestígio e que envolveria de forma surpreendentemente fervorosa toda a comunidade local irmanada num mesmo objectivo: a construção de uma cidade bela.

\section{A consolidação da cidade e a introdução do modernismo}

O crescimento da cidade da Beira, leva a que, em 1943 , as autoridades locais abram um concurso para a sua ampliação, situação única na então província de Moçambique que estava sujeita à acção do Gabinete de Urbanização Colonial, sedeado em Lisboa e que, a partir dali estabelecia através de anteplanos a forma urbana das cidades e demais povoados que se estabeleceriam nas suas colónias, mas também “[...] por causa da escassa capacidade técnica e autonomia financeira das administrações locais [...]" (Bruschi \& Lage 2005, p. 37), projecto esse que demonstra a pujança financeira da cidade. 0 projecto vencedor, da autoria de Ribeiro Alegre e José Porto, estaria envolto em polémica (Figura 7).

0 projecto proposto era arrojado, estilizando a malha ortogonal base, no sentido de dar prioridade à ampliação da cidade como forma de garantir o seu crescimento humano e comercial. No entanto, esse objectivo esbarrava com uma dificuldade técnica dada pela geologia do local: o carácter pantanoso do solo só permitiria a construção do edificado necessário se a implementação da planta proposta fosse sustentada num vasto conjunto de aterros e drenagem do solo,

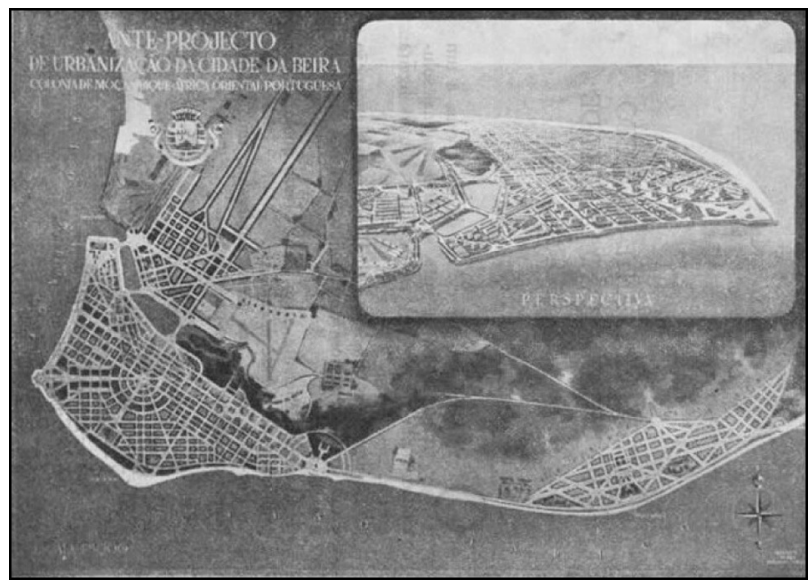

Figura 7 - Anteprojecto de Urbanização da Cidade da Beira, Arquitectos Ribeiro Alegre e José Porto (1943)

Fonte: Portugal (1946). que permitiria então, que se estruturasse a malha urbana num

[...] traçado cujo objectivo é continuar as preexistências, ainda que vincado por um desenho baseado em malhas ortogonais unidas por centros radiais. A proposta de zonamento é bem salientada no plano, diferenciando áreas administrativas, áreas comerciais, área turística e áreas residenciais distintas para a população europeia, asiática, mista e africana. Define-se ainda uma zona de carácter industrial e, bem assim, a localização da aerogare no bairro da Manga (Magalhães \& Gonçalves, 2009, p. 46).

A extinção da Companhia de Moçambique, em 1942, e a consequente nacionalização dos caminhos de ferro e do porto da cidade Beira, assente numa estratégia de desenvolvimento integrado da colónia possibilitada por uma forte concentração de poderes administrativos que o regime salazarista preconizava - cria a necessidade de expansão do parque habitacional para albergar os novos trabalhadores que à cidade aportam, conduzindo a um impulso urbanizador, embora fortemente zonado. Assim,

[...] no sector mais antigo da cidade os velhos edifícios de madeira ou de zinco tornam-se raros, substituídos progressivamente pelos de ferro e cimento de muitos andares. Adensam-se as construções, ampliam-se os problemas resultantes de uma especulação imobiliária desenfreada, porque fica aí a área de maior centralização de actividades económicas, com numerosos serviços públicos, sedes de bancos, companhias de seguros, consulados, profissões liberais, casas de modas e outros estabelecimentos comerciais, restaurantes, etc. (Amaral, 1969, p. 75).

A Beira fervilhava de vida cosmopolita, sendo uma cidade onde os equipamentos dedicados ao lazer se multiplicavam, mas que não perdia o seu foco naquilo que efectivamente possibilitava a ascensão de uma classe média desafogada e de uma posição de charneira regional: o negócio que permitia o afluxo de capitais que, por sua vez, permitiam o investimento, 0 crescimento e o desenvolvimento da cidade. Esse ímpeto urbanístico conhece especial sofreguidão durante a primeira metade da década de 1950, mas 
[...] em fins de 1956, inicia-se um novo surto de desenvolvimento [...] já de forma mais regular, tendendo a normalizar-se e permitindo que os vazios urbanísticos se vão enchendo. 0 aspecto de regularidade que o caso tomou é, na verdade, o que mais interessa no desenvolvimento da Beira. [...] ao ritmo de 9 projectos por semana, 20 por cento para construir e os restantes para aproveitamento de terrenos aforados, vão-se enchendo de construções os terrenos vazios da área urbanizada com arruamentos feitos e outros estão prontos a ser iniciados logo que até eles cheguem os acessos (Portugal, 1957, p. 165).

É por essa altura que a importância económica do turismo começa a ganhar um relevo crescente e determinante, constituindo-se a cidade como estância de veraneio para os turistas provenientes da África do Sul, Rodésia/Zimbabwe e Malawi que aqui aportavam e, desta forma, "[...] soon emerged hotels, restaurants and yacht clubs [...] offering water sports and an element of Latin culture [...]" (Newitt, 2009, p. 469). 0 turismo era a pedra de toque que faltava à cidade para que novos projectos para equipamentos específicos vissem a ordem do dia, assim como permitiria a expansão e desenvolvimento da cidade para novas áreas, acentuando-se a função turística em especial na sua linha de costa.

Apesar do afã que a cidade conhecia no sector da construção civil, com uma enorme quantidade de projectos a aparecerem de forma quase diária, a organização administrativa do projecto urbanístico da Beira é exemplar face a outros espaços e realidades, existindo toda uma estrutura organizacional que enquadrava o processo de intervenção na malha urbana de forma muito clara, precisa e organizada, pois estava regulamentado que

[...] na área central da cidade, apenas os arquitectos podiam assinar projectos (seguindo-se áreas onde já assinavam engenheiros, e depois, na periferia, agentes técnicos e desenhadores); os processos camarários respectivos incluíam nas telas finais os recibos de pagamento dos técnicos, e era obrigatória uma minuciosa descrição dos trabalhos e materiais a utilizar; finalmente um 'Conselho de Estética', renovado de 6 em 6 meses, formado por arquitectos e engenheiros, tudo supervisionava (Fernandes, 2005, p. 101).
Para culminar o cuidado com que a autarquia revestia a urbanização da cidade foi criado um prémio local de arquitectura - o prémio Araújo Lacerda - para premiar os projectos que mais se destacavam do ponto de vista formal e inovador. 0 crescimento da cidade era sentido pela população e pelos decisores como um objectivo comum e de tal forma estava enraizado o sentir a cidade e a ideia de que aquele era um espaço especial que era efectuada uma cobertura cuidada e sistemática das principais obras que se faziam na Beira pelos meios de comunicação local.

0 interesse pela arquitectura que se vivia então na cidade da Beira, a quantidade de projectos com interesse, muitos de elevado grau de dificuldade técnica na sua implementação, levou a que a cidade congregasse as atenções das colónias vizinhas de Moçambique, de tal forma que, em finais da década de (19)50, uma comissão de arquitectos da Rodésia/Zimbabwe deslocou-se àquela cidade com o intuito de estudar aquilo que era feito em termos arquitectónicos, mas também, ao nível da engenharia civil. Igualmente a projecção e atenções que concentrava levam a que cidade da Beira fosse anfitriã da realização de um Congresso Africano de Arquitectura (Cortês, 2011, p. 64).

A disponibilidade financeira e ânsia pelo prestígio através da arquitectura levam a que as intervenções urbanísticas e arquitectónicas passem a ser gradualmente intervenções de autor. Para tal contribuiu o ambiente de liberdade criativa que se vivia na cidade. Impulsionada pelo capital e necessidade de prestígio como forma de afirmação, aqui buscam o futuro jovens arquitectos, provenientes de Portugal, mas igualmente, com raízes em Moçambique e na Beira, arquitectos esses, influenciados pelas novas vagas arquitectónicas internacionais "[...] enquanto modo de resolução do 'problema da habitação', como ao mesmo tempo propõe um conhecimento profundo do contexto social, económico e geográfico específico da arquitectura portuguesa [...]" (Magalhães \& Gonçalves, 2009, p. 17) ali construindo obra de relevo e de síntese de culturas e influências estilísticas.

O seu território nacional - um Portugal bafiento - não era propício a essas ideias: o braço férreo da ditadura limitava a criação submetendo a arquitectura a fortes ditames de estilo. Nesse contexto, as colónias africanas, mais distantes do jugo de Lisboa com terras de amplos e vastos horizontes e oportunidades, revelavam-se o sítio ideal para a liberdade criativa, pois ali "[...] a censura imposta pelo regime de Salazar não havia 
atingido a produção e a linguagem arquitectónica [...]" (Cortês, 2011, p. 61), sendo possível a aplicação de novas ideias e estilos bebidos de fontes várias mas muito em especial, no modernismo brasileiro "[...] no seio de uma sociedade menos restritiva e mais distante do centro de poder, o que estes arquitectos tiveram em comum foi essa possibilidade de construir com um vocabulário moderno [...]" (Magalhães \& Gonçalves, 2009, p. 18). E desta forma, na paisagem urbana da Beira, surgem pitadas de outro estilo, de outras linguagens arquitectónicas inspiradas do Brasil que paulatinamente vêm a ganhar lugar na malha sua urbana adequando-se de forma surpreendente à cidade.

As influências do modernismo brasileiro na Beira como, de resto, na África Portuguesa - fazia-se sentir não apenas pela afinidade cultural ou estilística, mas igualmente porque

[...] do ponto de vista climático, o Brasil era muito semelhante ao que se podia encontrar na África portuguesa, existindo um conjunto enorme de soluções e técnicas já experimentadas e saberes sedimentados que poderiam ser transpostos com segurança para aquele contexto (Mendes, 2012b, p. 252).

De facto, as experiências modernistas no Brasil, mas também bebida noutras paragens, mostravam que "[...] a arquitectura modernista integrava-se simbioticamente à paisagem africana, denotando uma adaptabilidade às especificidades climáticas tropical, como demonstram diversas soluções e obras implementadas e executadas pelas diversas potências coloniais nos seus territórios ultramarinos [...]" (Mendes, 2012b, p. 253). É à inspiração no estilo e linguagem formal modernista brasileiro que muitas das soluções implementadas vão buscar referenciais tornando-se

[...] pertinentes nestes territórios a aplicação de elementos da arquitectura como os brise-soleil e os cobogós e as paredes parciais. Estes elementos, bem como a total supressão de paramentos exteriores permite aqui uma solução semelhante à corrente brasileira, privilegiando a relação interior-exterior, estabelecendo uma intensa relação dentro-fora desmaterializando os limites inamovíveis (Rebelo Fernandes, 2013, p. 175).

A linguagem modernista brasileira extravasa, no entanto, o espaço geográfico da África colonial portuguesa (na qual a produção registrada nas então províncias de Angola e de Moçambique assume contornos e volume a necessitar de inventariação e estudos), encontrando-se na África do Sul um dos grandes expoentes dessa corrente. Pela sua proximidade a Angola e Moçambique a produção sul-africana seria determinante para aquilo que se produzia nos seus vizinhos por efeito de transmissão de ideia e experiências. 0 principal veículo do modernismo brasileiro na região terá sido a Faculdade de Arquitectura de Pretória, cujo livro de estilo e principal corrente de ideias foi o catálogo Brazil Builds, que influenciaria uma geração de arquitectos ali formados (entre os quais alguns portugueses de Moçambique) e cuja produção arquitectónica na África do Sul seria marcada por aquele estilo (Perold, 2009, p. 43) ${ }^{3}$.

A década de 1950 vê emergir na cidade da Beira nomes que ficariam indelevelmente ligados à sua paisagem urbana como "[...] João Garizo do Carmo, Paulo Melo Sampaio ou Francisco Castro, que deixarão a cidade pontuada de edifícios públicos e residenciais marcados por uma linguagem moderna e influenciados pela obra que se desenvolvia então no Brasil [...]" (Magalhães \& Gonçalves, 2009, p. 46) mas, igualmente, Carlos Ivo, José Bernardino Ramalhete ou Eduardo Naia, entre outros, produziram as suas principais obras naquela cidade, "[...] dotando-a de um carácter modernista que não se esgota numa única leitura, tal o número de abordagens estéticas e o experimentalismo, no âmbito da engenharia civil, que provocaram num solo pouco próprio para a construção [...]" (Mendes, 2012b, p. 254) alicerçando a sua obra e opções estilísticas e práticas de construção na "[...] moderna arquitectura brasileira: grelhas de ventilação (cobogós), revestimentos cerâmicos, formas escultóricas de exceção a matrizes ortogonais e integração de murais, pinturas ou esculturas nos edifícios, tendendo à criação de obras de arte total [...]" (Miranda, 2012, p. 2).

Curiosamente é, segundo alguns dos arquitectos responsáveis por projectos simbólicos na cidade, à geologia, um dos maiores obstáculos à sua urbanização,

\footnotetext{
${ }^{3}$ A produção arquitectónica e urbanística inspirada pelo modernismo brasileiro é mais intenso do que à partida se poderia supor, encontrando-se marcas nas paisagens urbanas de Joanesburgo e de Pretória. De tal forma foi numerosa, que Nikolaus Pevsner, historiador de arte especialista em arquitectura, em 1953, se refere a Joanesburgo como "a little Brazil within the Commonwealth".
} 
além do clima, que se deve a opção pelo experimentalismo e opção estética pelo modernismo que consegue, no entanto, assumir uma identidade própria longe da cópia ou pastiche pois

[...] a proliferação de edifícios com estruturas 'especiais' próximas de um imaginário 'brasiliano' deve-se, segundo os seus arquitectos, às características pantanosas de parte dos solos que compõem a cidade, mas também ao 'prazer' dos engenheiros locais em 'calcular estruturas'. O partido geral do edificado 'moderno' decorre, ainda de acordo com o [arquitecto] Francisco de Castro, das questões de arejamento (em detrimento da protecção solar) o que para este arquitecto significa uma abordagem distinta da solução brasileira padrão (Milheiro \& Ferreira, 2009, p. 13).

\section{Sinais emblemáticos do modernismo brasileiro na malha urbana}

A influência do modernismo brasileiro é reconhecível por toda a cidade. As obras de arquitectos brasileiros serviram de inspiração e/ou referência conceptual a arquitectos estabelecidos na Beira contribuindo para o acentuar das mudanças que a cidade conhece na sua malha e paisagem urbana. Em década e meia conhece um intenso frenesi de criatividade arquitectónica e de engenharia civil - que nem a eclosão da guerra pela independência soube calar - período durante o qual muitos arquitectos deixam a sua marca, contribuindo indelevelmente, para uma imagem urbana própria que fazem dela uma cidade modernista na África tropical.

Muitos são os arquitectos e as obras que poderão ser listados como modernistas, sendo igualmente possível identificar um punhado de edifícios que pelo seu valor e simbolismo se destacam na paisagem e no seu imaginário da cidade e mesmo do país.

$\mathrm{Na}$ área residencial da Manga, foi erigida, com projecto do arquitecto João Garizo do Carmo, a Igreja Matriz da Manga (Figura 8), uma de suas obras mais importantes e marcantes da paisagem urbana da Beira, aparentemente inspirada num dos símbolos do modernismo brasileiro, nomeadamente a igreja de S. Francisco de Assis, na Pampulha (Brasil), projectada por Oscar Niemeyer. A igreja Matriz da Manga é um edifício estruturado pela sua abóbada parabólica em betão, com o seu corpo decorado por um mural em azulejaria, sendo clara a sua inspiração no modelo brasileiro tanto no corpo do edifício como na (re) interpretação da torre sineira.

Na zona turística da Beira, no Macúti, próximo das praias de areia branca e águas cálidas, localiza-se outro dos edifícios modernistas emblemáticos da cidade, o Motel Estoril (Figura 9), de Paulo de Melo Sampaio (igualmente responsável pelo plano de pormenor

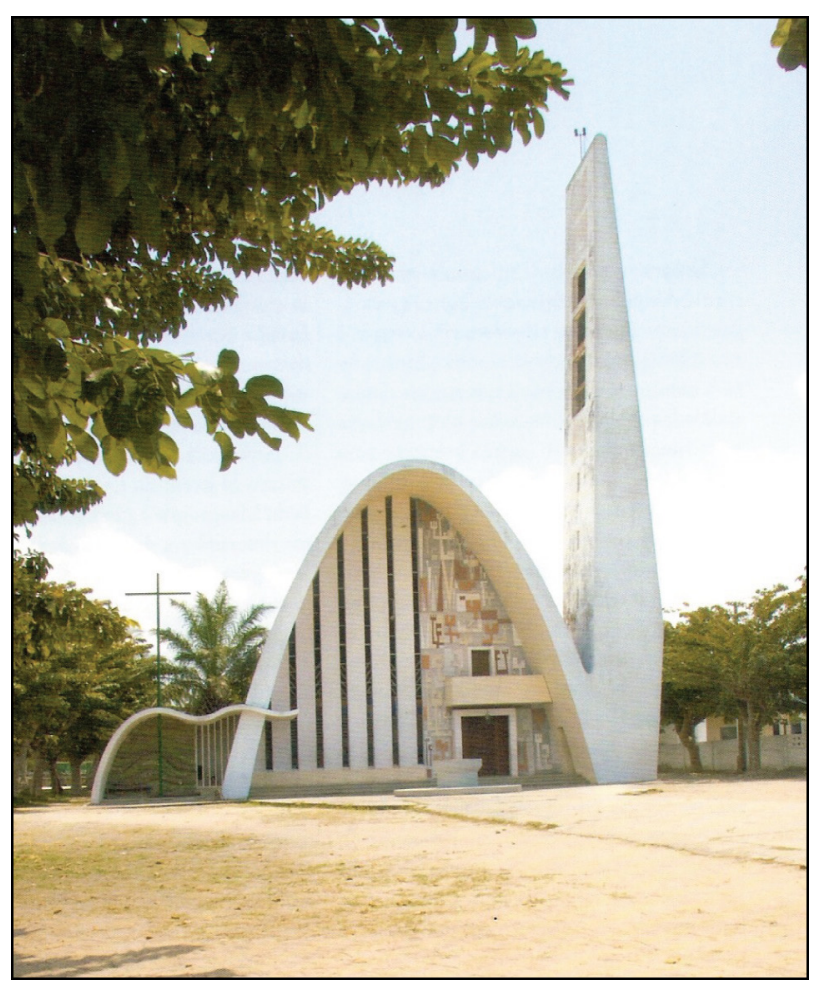

Figura 8 - Igreja da Manga, Projecto do Arquitecto João Garizo do Carmo Fonte: Magalhães \& Gonçalves (2009).

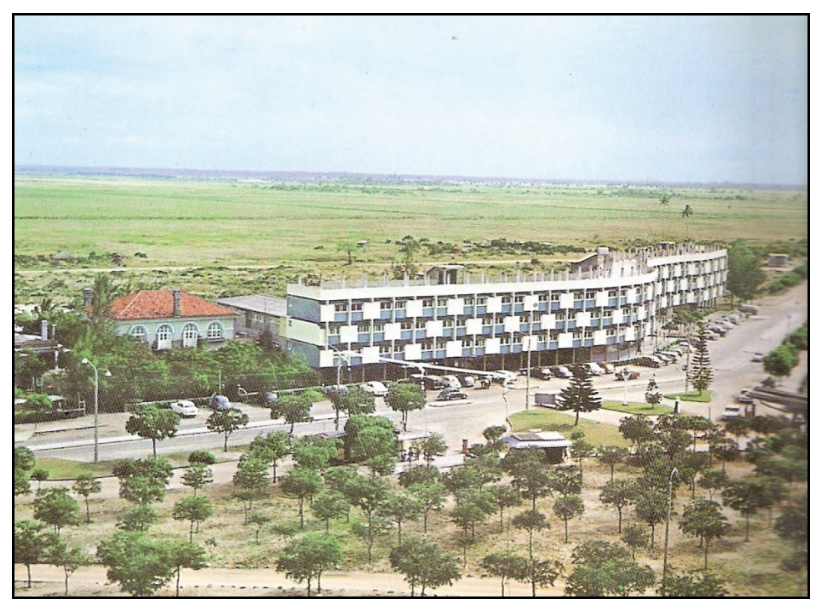

Figura 9 - Motel Estoril, Macúti (1965), Projecto do Arquitecto Paulo Melo Sampaio

Fonte: Loureiro (2008). 
turístico da área em que se implanta o edifício, o Complexo Turístico do Estoril, que procurava estruturar o potencial que o turismo começava a ter como fonte geradora de capitais), remetendo para a obra do arquitecto brasileiro Afonso Eduardo Reidy e o seu Conjunto Habitacional Pedregulho, no Rio de Janeiro. É um edifício de planta ondulante - mimetizando e potenciando a topografia do local - de três pisos (com um quarto piso de acrescento posterior à sua construção), assente em pilotis que erguem o corpo do edificado do solo.

Pela sua localização, estado de conservação e qualidade do edifício, o Motel Estoril, actualmente devoluto, tem suscitado interesse de grupos da indústria hoteleira em proceder à sua reabilitação e viabilização, aproveitando o crescente interesse que a Beira tem suscitado ao nível da demanda de turistas.

Com o eclodir da guerra colonial a produção arquitectónica não se ressente e a produção de vulto e edifícios marcantes continua a acontecer por toda a cidade, constituindo também, uma forma de Portugal demonstrar a supremacia da potência colonial face às aspirações independentistas e às críticas provenientes do exterior ao regime colonial, projectando uma imagem de estabilidade e continuidade, surgem uma série de equipamentos de cariz modernista.

De entre o edificado do período, destacam-se pelo seu investimento, dimensões e qualidade, o projecto do aeroporto da Beira (1965, Figura 10), da autoria de Cândido Palma de Melo, na altura de maiores dimensões que o de Lourenço Marques/Maputo, consistindo num bloco paralelepipédico com duas fachadas com tratamento distinto consoante se direccione para a pista ou para a cidade; a Casa dos Bicos, desenhado por João Garizo do Carmo, edifício assim conhecido pelo formato do seu telhado com dez lâminas em betão, sustentadas num edifício corpo $3.250 \mathrm{~m}^{2} \mathrm{e}$ uma fachada de $125 \mathrm{~m}$. Finalmente, as Piscinas do Clube Ferroviário da Beira, 1970 Figura 11, um “[...] edifício-muro, destinado a serviços de apoio, aberto sobre as piscinas, com uma cobertura constituída por uma sequência de abóbadas catalãs [...]" (Magalhães \& Gonçalves, 2009, p. 229).

No núcleo urbano da cidade localiza-se o cinema S. Jorge, um dos muitos equipamentos culturais que a cidade teve, um edifício constituindo por três corpos intersectados com volumetrias diversas, no qual o corpo predominante é trapezoidal estruturado sob forma de leque, recortado por um brise-soleil.
Adjacente ao núcleo urbano, domina o Grande Hotel da Beira (Figura 12) que, pela sua dimensão e desmesura arquitectónica, viria a constituir um marco

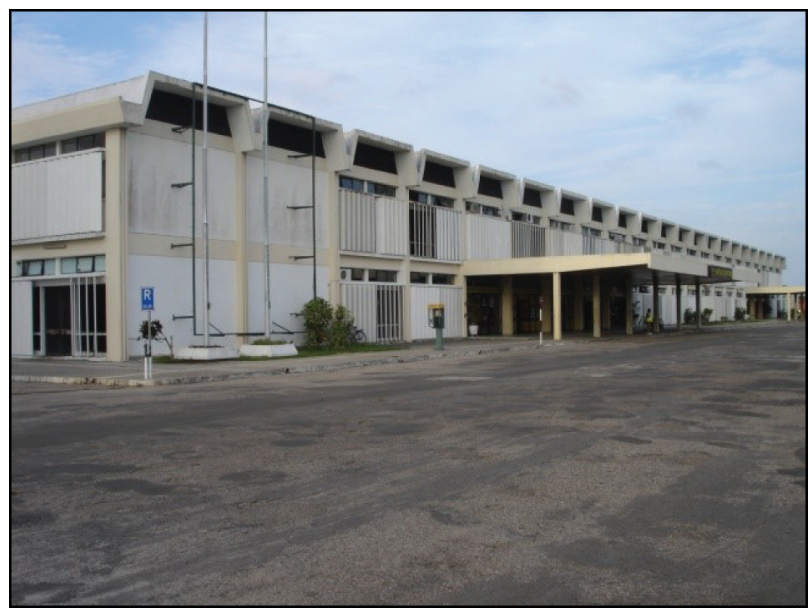

Figura 10 - Aerogare do Aeroporto da Beira

Fonte: Arquivo dos autores (2011). Trabalho de campo.

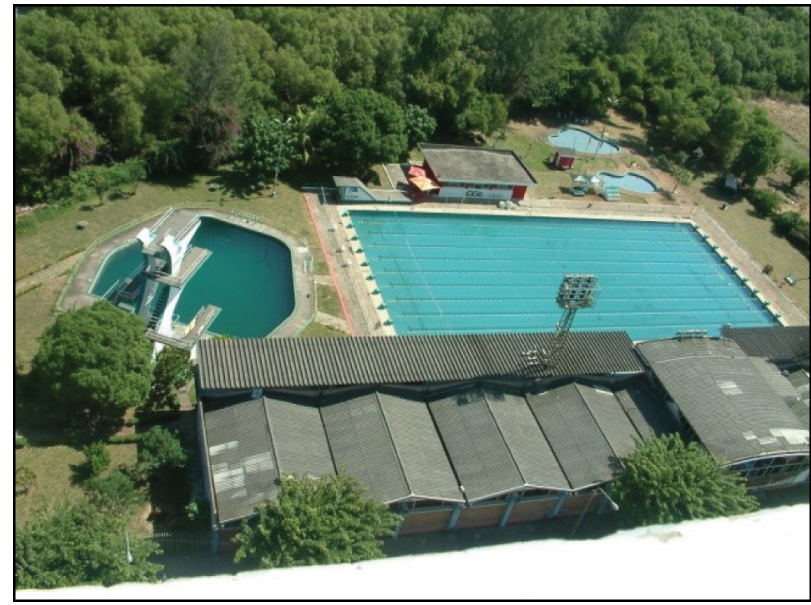

Figura 11 - Piscinas do Clube Ferroviário da Beira Fonte: Arquivo dos autores (2011). Trabalho de campo.

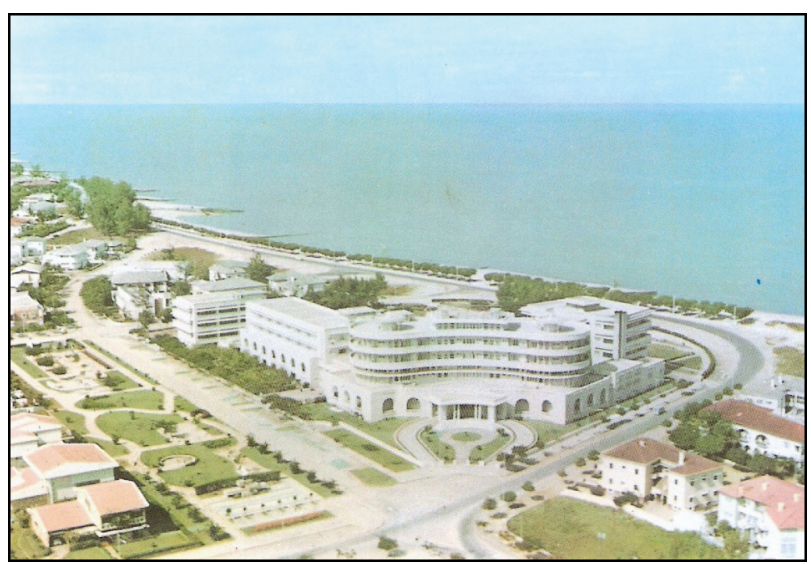

Figura 12 - Grande Hotel da Beira (c. 1957), Projecto do Arquitecto José Porto Fonte: Loureiro (2008). 
no urbanismo da Beira. 0 Hotel foi projectado por José Porto, um dos responsáveis pelo projecto de ampliação da cidade, localizando-se junto ao mar numa área de implantação com 12 mil m², onde, além do Hotel, se incluía uma piscina olímpica e um casino. Iniciadas as obras em 1953, foram concluídas em 1955, um ano depois do previsto e com uma enorme derrapagem financeira. É um edifício de fachada arredondada, em diversos blocos de planta rectangular.

O Hotel acabou por encerrar dois anos após a sua inauguração por falta de clientela e por sempre lhe ter sido negada a abertura naquele espaço de um casino, o que condenou à partida todo o projecto de sustentabilidade, num jogo político envolvendo o concessionário dos casinos da Rodésia/Zimbabwé, que terá movido as suas influências para evitar a abertura de concorrência directa em Moçambique.

Actualmente, o edifício serve de alojamento a cerca de duas mil pessoas que ali vivem em condições precárias, desconhecendo-se planos para o seu futuro e/ou realojamento dos seus habitantes. No entanto, a sua reabilitação afigura-se tecnicamente difícil de efectuar em virtude do seu avançado estado de degradação.

Defronte da (agora carcaça) do Grande Hotel da Beira, localiza-se o antigo Automóvel Touring Clube de Moçambique (actual Palácio dos Casamentos) (Figura 13), construído em 1957, com projecto do Arquitecto Paulo de Melo Sampaio,

[...] é um volume curvilíneo de um só piso, parcialmente levantado do solo, intersectado por um volume vertical aberto que contém as escadas, disposto de forma assimétrica na fachada. 0 corpo suspenso é rasgado por uma enorme abertura horizontal, que corresponde ao núcleo das escadas [...]. A caixa das escadas é contida por uma pala em betão e um grande plano revestido a pastilha vidrada com desenhos geométricos (Magalhães \& Gonçalves, 2009, p. 227).

Junto ao edifício, um mural em pedra esculpida retrata motivos africanos.

A Estação dos Caminhos-de-Ferro da Beira (Figura 14) será o expoente máximo do modernismo de influência brasileira na cidade da Beira, ex libris da cidade e um dos mais grandiosos e importantes edifícios da arquitectura colonial portuguesa. 0 projecto da Estação foi elaborado por três arquitectos - ao tempo, todos com provas dadas na cidade, cada qual responsável por uma parte do corpo da Estação: a gare da responsabilidade de Paulo Melo Sampaio, enquanto que os terminais são atribuídos a João Garizo do Carmo e o edifício de escritórios a Francisco Castro (Magalhães \& Gonçalves, 2009, p. 228).

Os três corpos geram um conjunto assimétrico mas integrado e harmonioso onde "[...] a gare é, [...], o edifício mais marcante, embora todo o conjunto tenha um sentido coerente [...]" (Magalhães \& Gonçalves, 2009 , p. 228) o qual apesar da sua volumetria se encontra perfeitamente incorporado na paisagem. Por sua vez, o edifício de escritórios da estação é constituído por sete pisos "[...] que simulam, através da estrutura aparente 'caixas' sobrepostas criando longas aberturas na transição entre os pisos [...]”

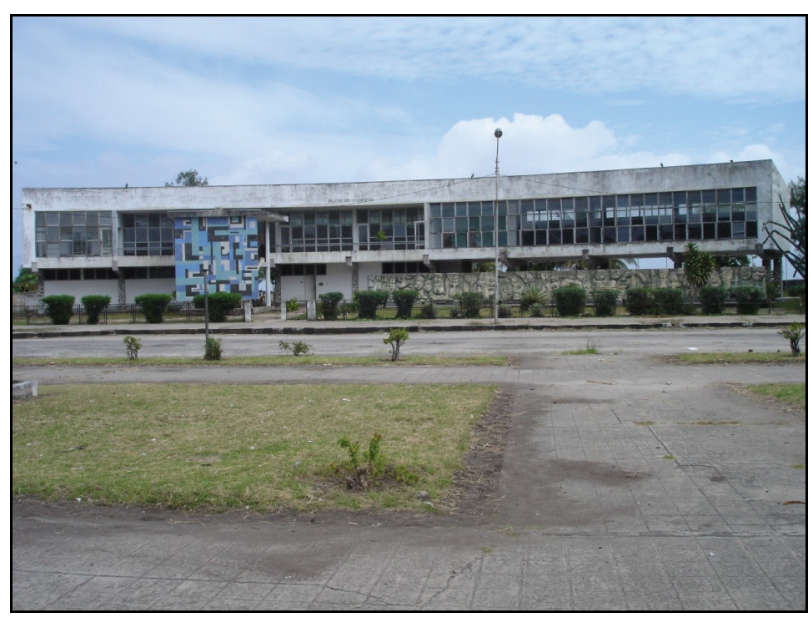

Figura 13 - Palácio de Casamentos (antigo Automóvel Touring Clube de Moçambique)

Fonte: Arquivo dos autores (2011). Trabalho de campo.

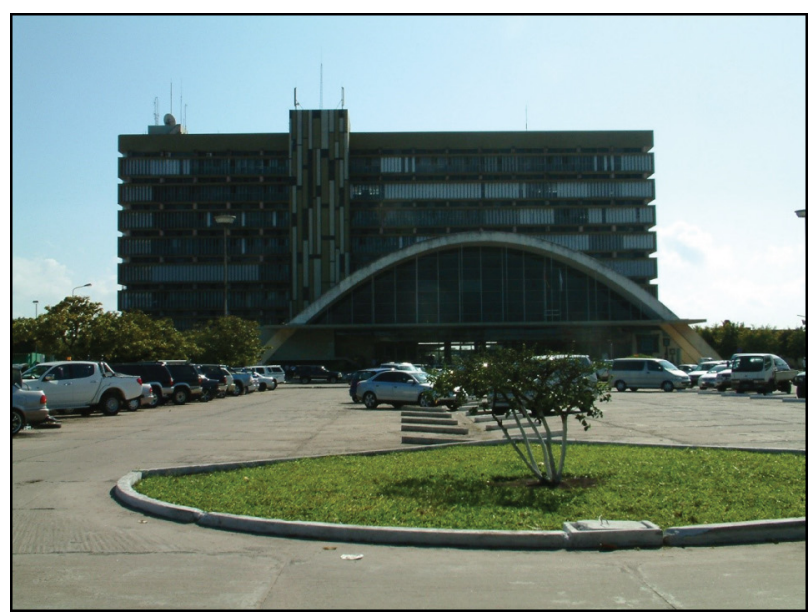

Figura 14 - Estação da Beira (1967), Projecto dos Arquitectos Paulo Melo Sampaio, João Garizo do Carmo e Francisco Castro Fonte: Arquivo dos autores (2011). Trabalho de campo. 
(Magalhães \& Gonçalves, 2009, p. 228), estando projectado sob a forma de um paralelepípedo assente sobre pilotis, de clara inspiração em Le Corbusier, mas igualmente remetendo à estrutura dos primeiros edifícios da cidade assim construídos como forma de se defenderem das cheias dos rios vizinhos, existindo actualmente alguns poucos vestígios desse período inicial da urbanização do então povoado. No entanto, a forma como os corpos dos diferentes edifícios se cruzam, a função da parabolóide da estação, parece remeter para outra obra de Niemeyer: o Hospital Sul-América.

A fachada da Estação (Figuras 15 e 16), as paredes exteriores laterais e mesmo o interior da Estação estão decorados com mosaico, ora remetendo para motivos relacionados com a função da Estação, ora para um certo imaginário estilístico africano.

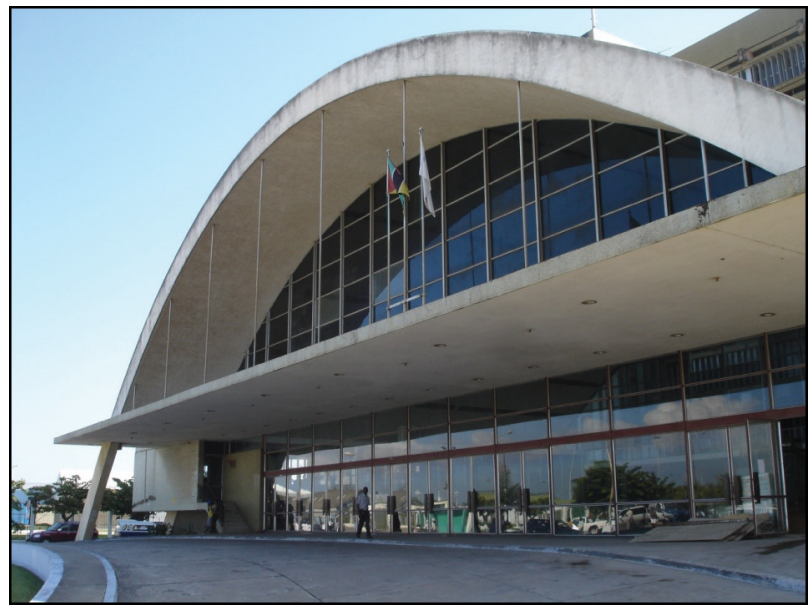

Figura 15 - A Estação da Beira

Fonte: Arquivo dos autores (2011). Trabalho de campo.

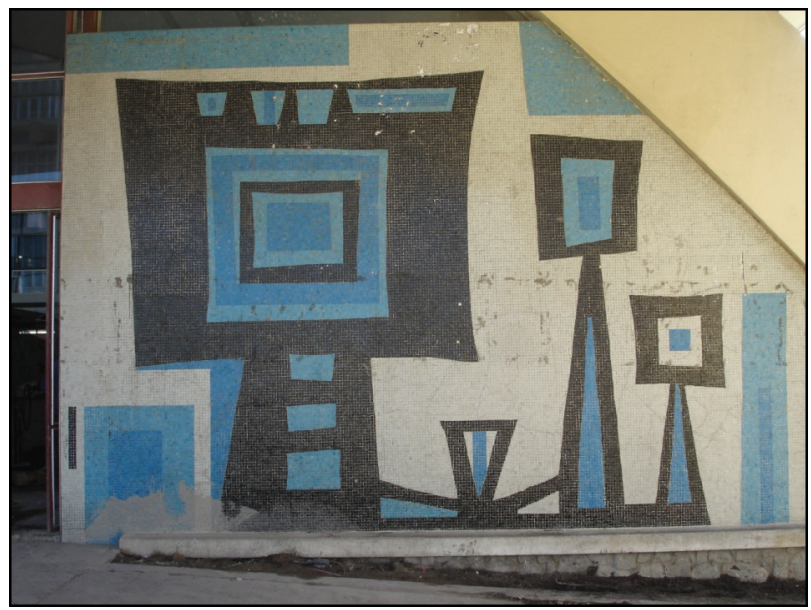

Figura 16 - Pormenores fachada e latera da Estação da Beira Fonte: Arquivo dos autores (2011). Trabalho de campo.
As marcas modernistas na África Portuguesa, e em especial na cidade da Beira, atestam o percurso de inúmeros arquitectos que intervencionaram o território, os quais de entre as diversas influências que beberam se inspiram de forma determinante nos conceitos da arquitectura modernista brasileira, de tal forma que “[...] Portugal foi assim o 'caso único' de uma nação com regime político retrógrado, a nível europeu, que teve uma produção de vanguarda inovadora no seu espaço colonial africano [...]" (Fernandes, 2002, p. 31) que soube sintetizar influências, estilos e técnicas de diversas proveniências e culturas, dotando as urbes das suas colónias com um carácter distintivo muitas vezes inesperado.

\section{Referências}

Amaral, I. (1969). Beira, cidade e Porto do Índico. Finisterra Revista Portuguesa de Geografia, 4(7), 76-93.

Bruschi, S., \& Lage, L. (2005). Moçambique, o desenho das cidades: Moçambique até o século XXI. Maputo: FAPF.

Cortês, C. M. (2011). Moderno brasileiro em Moçambique, 1950-1975: a importação de uma imagem (Dissertação de mestrado). Universidade Federal de Pernambuco, Recife.

Fernandes, J. M. (2002). Geração africana: arquitectura e cidades em Angola e Moçambique, 1925-1975. Lisboa: Livros Horizonte.

Fernandes, J. M. (2005). Arquitectura e urbanismo na África Portuguesa. Lisboa: Caleidoscópio.

Herskovits, M. J. (2014). Winterton Collection of East African Photographs (1860-1960). Illinois: Library of African Studies.

Loureiro, J. (2008). Moçambique. Lisboa: João Loureiro e Associados.

Magalhães, A., \& Gonçalves, I. (2009). Moderno Tropical, Arquitectura em Angola e Moçambique, 1948-1975. Lisboa: Tinta-da-China.

Mendes, R. P. (2012a). A Cidade colonial e a estruturação do território em Moçambique: a evolução urbana de Lourenço Marques/Maputo, Beira, Nampula e Porto Amélia/Pemba. 2012 (Dissertação de mestrado). Faculdade de Letras, Universidade do Porto, Porto.

Mendes, R. P., (2012b). 0 modernismo e suas abordagens no espaço lusófono. urbe. Revista Brasileira de Gestão Urbana, 4(2), 245-257. 
Milheiro, A.V., Ferreira, J.F., (2009). A Joyous Architecture: as exposições de arquitectura moderna brasileira em Portugal e a sua influência nos territórios português e africano. In $8^{\circ}$ Seminário Docomomo Brasil, Cidade Moderna e Contemporânea: Síntese e Paradoxo das Artes. Rio de Janeiro.

Miranda, E. (2012). No caminho de uma arquitetura racional: infraestruturas modernas em Moçambique. In Colóquio Internacional Portugal-Brasil-África: Urbanismo e Arquitectura: do Ecletismo ao Modernismo. Lisboa.

Muhate, I., (1989). Alguns aspectos do retrato histórico e prospectivo do porto da Beira, arquivo [Número especial]. Boletim do Arquivo Histórico da Beira, 6, 297-346.

Newitt, M. (2009). A history of Mozambique. London: Hurst \& Company.

Perold, M. (2009). Music2: extension and conversion of the Department of Music of the University of Pretoria. (Dissertação de mestrado). Faculdade de Engenharia, Ambiente Construído e Tecnologia da Informação, Universidade de Pretoria, Pretoria.

Portugal. Agência Geral das Colónias. (1946). Acerca do Anteprojecto de Urbanização da cidade da Beira. Boletim Geral das Colónias, XXII(229), 52-68.
Portugal. Agência Geral do Ultramar, Cinquentenário da Cidade da Beira. (1957). Boletim Geral do Ultramar, XXXIII(390), 232, 165-177.

Rebelo Fernandes, M. (2013). A Arquitectura brasileira num dos vêrtices do Triângulo Portugal/África/Brasil: o seu papel na divulgação do Movimento Moderno em Angola e Moçambique (Dissertação de mestrado). Instituto Superior Técnico, Lisboa.

Silveira, L. (1955). Ensaio de iconografia das cidades portuguesas do Ultramar (Vol. 2). Ultramar: Ministério do Ultramar, Junta de Investigações do Ultramar.

Sopa, A. (1989). Condições de habitabilidade numa pequena povoação costeira da África Austral, 1892-1925, Cidade da Beira, arquivo [Número especial]. Boletim do Arquivo Histórico da Beira, 6, 5-64.

United Nations Office for the Coordination of Humanitarian Affairs - OCHA. (2015). Mozambique 2015. New York. Recuperado em 9 de fevereiro de 2015, de http://www. unocha.org/cerf/cerf-worldwide/where-we-work/moz-2015.

Recebido: Fev. 09, 2015

Aprovado: Maio 04, 2015 